\title{
Atlantic moonfishes: independent pathways of karyotypic and morphological differentiation
}

\author{
Uedson Pereira Jacobina • Marcelo Ricardo Vicari • \\ Pablo Ariel Martinez $\cdot$ Marcelo de Bello Cioffi • \\ Luiz Antonio Carlos Bertollo · Wagner Franco Molina
}

Received: 6 June 2012/Revised: 27 October 2012/ Accepted: 1 November 2012/Published online: 21 November 2012

(C) Springer-Verlag Berlin Heidelberg and AWI 2012

\begin{abstract}
Fish of the genus Selene, known as lookdowns or moonfish, are one of the most morphologically derived groups of the family Carangidae, whose phylogenetic relationships are still largely unknown. In this study, we discuss karyoevolutionary aspects of three representatives of this genus from the Western Atlantic: Selene brownii $(2 n=48 ; \quad \mathrm{FN}=48), \quad$ Selene setapinnis $(2 n=46$; $\mathrm{FN}=48)$, and Selene vomer $(2 n=48 ; \mathrm{FN}=50)$. Their body patterns were also investigated and compared to one another and in relation to two other species of different genera. Two mechanisms of karyotypic evolution seem to have acted in the diversification of this genus, namely pericentric inversions and centric fusions. Mapping of rDNA sequences showed that chromosome pairs bearing 5S rDNA sites are similar, whereas those bearing $18 \mathrm{rDNA}$ sites are morphologically distinct while apparently also exhibiting interspecies synteny. Although the nucleolar organizer-bearing chromosomes are extremely efficient cytotaxonomic markers among Selene species, others
\end{abstract}

Communicated by H.-D. Franke.

U. P. Jacobina ( $\varangle)$ · P. A. Martinez · W. F. Molina Departamento de Biologia Celular e Genética, Centro de Biociências, Universidade Federal do Rio Grande do Norte, Natal, RN, Brazil

e-mail: uedsonbio@gmail.com

\section{R. Vicari}

Laboratório de Citogenética e Evolução,

Departamento de Biologia Estrutural, Molecular e Genética, Universidade Estadual de Ponta Grossa,

Ponta Grossa, PR, Brazil

M. de Bello Cioffi - L. A. C. Bertollo

Departamento de Genética e Evolução, Centro de Ciências Biológicas e da Saúde, Universidade Federal de São Carlos, São Carlos, SP, Brazil cytogenetic patterns of these species are relatively conserved. Hybridization with telomeric probes (TTAGGG) did not exhibit interstitial telomeric sites (ITS), especially in $S$. setapinnis, where, along with a reduction in diploid number, a large metacentric pair derived from centric fusion is present. Data obtained by geometric morphometrics enable a clear morphological distinction among the three species, as well as in relation to two other species of the genus Caranx and Oligoplites. Data obtained suggest that morphologic evolution in Selene species was primarily dissociated from visible changes that occurred at the chromosomal level.

Keywords Selene Pericentric inversions . Centric fusion - Morphological divergence

\section{Introduction}

Fish of the genus Selene, known as lookdowns or moonfish, belong to one of the most morphologically derived groups compared to the 32 genera that make up the family $\mathrm{Ca}$ rangidae. Indeed, they exhibit a tall round body, laterally compressed, with a unique steep head (Smith-Vaniz 1979). This genus is composed of only the following seven species: Selene brownii (Cuvier 1816), Selene setapinnis (Mitchill 1815), Selene vomer (Linnaeus 1758), in the Western Atlantic, Selene dorsalis (Gill, 1862), in the Eastern Atlantic, and Selene peruviana (Guichenot 1866), Selene brevoorti (Gill 1863), and Selene orstedii (Lütken, 1880), in the Eastern Pacific.

Phylogenetic relationships among Selene species are scarcely known, where there is no uniquely derived character identified for this genus putting your taxonomic composition in family Carangidae still in question (Smith-Vaniz 1984). 
From a morphological standpoint, the absence of an exclusive diagnostic character for Selene makes its taxonomic composition questionable, for example, validation of the species S. setapinnis and S. brownii, whose differentiation characters significantly overlap (Smith-Vaniz 1979). Analyses based on cytochrome $b$ gene sequencing have as yet not been able to explain relationships among its species (Reed et al. 2001). Questions remain concerning the real phylogenetic positioning and monophyletism of this genus, although the differentiation of marine species in many groups is not seem to have been followed by significant karyotype diversification (Brum and Galetti 1997).

Rearrangements in the chromosome complement are often associated with speciative processes, favoring their use in phylogenetic and evolutionary analyses (King 1993). Scant cytogenetic information is available for Atlantic species of Carangidae (Rodrigues et al. 2007) in contrast to Mediterranean species, which are the focus of most cytogenetic studies (Caputo et al. 1996; Sola et al. 1997; Chai et al. 2009).

In order to compare evolutionary aspects of the karyotype and establish a possible relationship with its diversified body shapes, the species $S$. brownii, S. setapinnis and $S$. vomer, occurring in the Western Atlantic, were analyzed cytogenetically by conventional staining, Ag-NORs, C-banding, chromomycin $\mathrm{A}_{3}$ (CMA) and 4',6-diamidino-2phenylindole (DAPI) staining, and mapping of $18 \mathrm{~S}, 5 \mathrm{~S}$ rDNA and telomeric sequences, as well as by geometric morphometrics. Both methodologies were able to discriminate species, showing their chromosomal evolution and validating the sibling species $S$. brownii and S. setapinnis.

\section{Materials and methods}

Cytogenetic analyses were conducted with the Caribbean moonfish Selene brownii $(n=8)$, Atlantic moonfish S. setapinnis $(n=7)$, and the Atlantic lookdown $S$. vomer $(n=7)$ from the coast of Rio Grande do Norte State $\left(05^{\circ} 05^{\prime} 26^{\prime \prime} \mathrm{S} / 36^{\circ} 16^{\prime} 31^{\prime \prime} \mathrm{W}\right)$, Northeastern Brazil. Before chromosomal preparations, specimens were submitted to in vivo mitotic stimulation for $24 \mathrm{~h}$, by intramuscular and intraperitoneal inoculation of bacterial and fungal antigen complexes (Molina et al. 2010). Specimens were anesthetized with clove oil (Griffiths 2000) and then killed. Metaphase chromosomes were obtained from cell suspensions of the anterior kidney, using short-term in vitro methodology (Gold et al. 1990).

\section{Chromosome banding}

Heterochromatic regions and ribosomal sites were identified with techniques described by Sumner (1972) and
Howell and Black (1980), respectively. $\mathrm{CMA}_{3} / \mathrm{DAPI}$ double staining was employed, using DAPI as counterstain (Barros-e-Silva and Guerra 2010). Briefly, slides aged for 3 days were stained with $\mathrm{CMA}_{3}(0.1 \mathrm{mg} / \mathrm{ml})$ for $60 \mathrm{~min}$ and retained with DAPI $(1 \mu \mathrm{g} / \mathrm{ml})$ for $30 \mathrm{~min}$. Next, the slides were mounted in glycerol:McIlvaine buffer pH 7.0 (1:1) and aged for 3 days before being analyzed with an epifluorescence microscope under appropriate filters.

\section{Cytogenetic mapping}

Three probes were used: an 18S rDNA probe obtained from the nuclear DNA of Prochilodus argenteus Spix and Agassiz, 1829 (Hatanaka and Galetti 2004), a 5S rDNA probe isolated from the genomic DNA of Leporinus elongatus Valenciennes, 1850 (Martins and Galetti 1999), and a probe for the general vertebrate telomeric sequence $(\text { TTAGGG })_{\mathrm{n}}$ (Ijdo et al. 1991). Probes were labeled through polymerase chain reaction (PCR), using biotin-16dUTP (Roche Applied Science) for rDNA 18S, or digoxygenin-11-dUTP (Roche Applied Science) for rDNA 5S and $(\mathrm{TTAGGG})_{\mathrm{n}}$ probes. Polymerase chain reaction labeling using specific primers was performed for rDNA clones using $20 \eta \mathrm{g}$ of template DNA, 1X Taq Reaction buffer (200 mM Tris pH 8.4, $500 \mathrm{mM} \mathrm{KCl),} 40 \mu \mathrm{M}$ dATP, dGTP and dCTP, $28 \mu \mathrm{M}$ of dTTP, $12 \mu \mathrm{M}$ biotin-16-dUTP or digoxygenin-11-dUTP, $1 \mu \mathrm{M}$ primers, $2 \mathrm{mM} \mathrm{MgCl}_{2}$ and $2 \mathrm{U}$ of Taq DNA polymerase (Invitrogen) under the following conditions: $5 \mathrm{~min}$ at $94{ }^{\circ} \mathrm{C}$; 35 cycles: $1 \mathrm{~min}$ at $90{ }^{\circ} \mathrm{C}, 1 \mathrm{~min} 30 \mathrm{~s}$ at $52{ }^{\circ} \mathrm{C}$ and $1 \mathrm{~min} 30 \mathrm{~s}$ at $72{ }^{\circ} \mathrm{C}$; and a final extension step at $72{ }^{\circ} \mathrm{C}$ for $5 \mathrm{~min}$. The reaction for labeling the telomeric probe involved $1 \times$ Taq Reaction buffer, $40 \mu \mathrm{M}$ dATP, dGTP, and dCTP, $28 \mu \mathrm{M}$ of dTTP, $12 \mu \mathrm{M}$ of digoxygenin-11-dUTP, $0.2 \mu \mathrm{M}$ primer (TTAGGG) 5, $0.2 \mu \mathrm{M}$ primer (CCCTAA) 5, $2 \mathrm{mM} \mathrm{MgCl}_{2}$, and $2 \mathrm{U}$ of Taq DNA polymerase, under the following conditions: the first amplification was performed with low stringency: $4 \mathrm{~min}$ at $94{ }^{\circ} \mathrm{C}, 12$ cycles of $1 \mathrm{~min}$ at $94{ }^{\circ} \mathrm{C}$, $45 \mathrm{~s}$ at $52^{\circ} \mathrm{C}$ and $1 \mathrm{~min} 30 \mathrm{~s}$ at $72^{\circ} \mathrm{C}$, followed by 35 high stringency cycles: $1 \mathrm{~min}$ a $94{ }^{\circ} \mathrm{C}, 1 \mathrm{~min} 30 \mathrm{~s}$ at $60{ }^{\circ} \mathrm{C}$, and $1 \mathrm{~min} 30 \mathrm{~s}$ at $72{ }^{\circ} \mathrm{C}$.

The overall hybridization procedure followed the protocol described by Pinkel et al. (1986), under high stringency conditions $(2.5 \mathrm{mg} / \mu \mathrm{l}$ from each probe, $50 \%$ deionized formamide, $10 \%$ dextran sulfate, 2XSSC, $\mathrm{pH}$ 7.0-7.2, at $37{ }^{\circ} \mathrm{C}$ overnight). After hybridization, slides were washed in $15 \%$ formamide/0.2XSSC at $42{ }^{\circ} \mathrm{C}$ for $20 \mathrm{~min}, 0.1 \mathrm{XSSC}$ at $60{ }^{\circ} \mathrm{C}$ for $15 \mathrm{~min}$, and $4 \mathrm{XSSC} / 0.05 \%$ Tween at room temperature for $10 \mathrm{~min}$, the latter consisting of two 5-min washes. Signal detection was performed using streptavidin-alexa fluor 488 (Molecular Probes) for $18 \mathrm{~S}$ rDNA, and anti-digoxigenin-rhodamine (Roche Applied Science) for 5S rDNA and (TTAGGG)n probes. 
One-color FISH was performed to detect (TTAGGG), while $5 \mathrm{~S}$ and $18 \mathrm{~S}$ rDNA were detected by dual-color FISH.

\section{Chromosome analyses}

Chromosomes were analyzed under an epifluorescence microscope (Olympus BX41) coupled to an image capturing system (Olympus DP71). Approximately 30 metaphases of each species were analyzed to establish the diploid number and karyotype structure, as well as to map rDNA sites and eventual ITS (Interstitial telomeric sites) on the chromosomes. Hybridization signals exhibiting $100 \%$ repeatability were considered genuine. Chromosomes were classified as metacentric (m), submetacentric (sm), subtelocentric (st), and acrocentric (a), based on the system proposed by Levan et al. (1964).

\section{Morphometrics analyses}

Geometric morphometrics methods were used to compare body patterns of $S$. brownii $(n=20), S$. setapinnis $(n=15), S$. vomer $(n=17)$, and Oligoplites palometa (Cuvier 1832) $(n=15)$, from the coast of Natal, Rio Grande do Norte state and Caranx lugubris (Poey 1860) $(n=15)$, from the São Pedro and São Paulo Archipelago. In view to minimize possible distortions due allometric effects, only adult individuals were used to the measurements.

Specimens of each species were individually photographed (right side view), with an 8.1 megapixel Sony DSC-H10 digital camera. Body shapes were analyzed using 12 landmarks (Fig. 2), defined by tps Dig 21.40 software (Rohlf 2004). Configurations of body landmarks were overlapped using generalized procrustes alignment (Rohlf and Slice 1990; Dryden and Mardia 1998). Analyses of canonical variates were performed to discriminate and quantify the magnitude of morphological divergence. Intergroup significance levels were determined by Hotelling T2 statistic and the permutation test (1,000 times). Interspecies morphological differences were illustrated by the thin-plate spline method, using wireframe graphs. All analyses were carried out with MorphoJ 1.02 software (Klingenberg 2008).

\section{Results}

Cytogenetic analyses

Selene brownii exhibited karyotype composed of $2 n=48$ acrocentric chromosomes ( $\mathrm{FN}=48$ ) (Fig. 1; left column). Reduced heterochromatic blocks are present in the pericentric region of most chromosomes and, in some pairs, in the terminal region. Dual-color FISH with $18 \mathrm{~S}$ and $5 \mathrm{~S}$ rDNA showed non-syntenic location between these ribosomal subunits. The $18 \mathrm{~S}$ rDNA sites are unique and coincident with the $\mathrm{Ag}-\mathrm{NOR}^{+} / \mathrm{C}-\mathrm{band}^{+} / \mathrm{CMA}^{+} / \mathrm{DAPI}^{-}$region of chromosome 1 . The $5 \mathrm{~S}$ rRNA genes are positioned in the pericentromeric region of chromosome pair 9, co-located with a conspicuous heterochromatic region.

Selene setapinnis showed karyotype with $2 n=46$ $(\mathrm{FN}=48), 44$ acrocentric chromosomes and two large metacentric chromosomes (Fig. 1; central column). Small heterochromatic blocks are present in the pericentromeric regions of most chromosomes. In situ hybridization with $18 \mathrm{~S}$ and $5 \mathrm{~S}$ rDNA probes indicates the location of these ribosomal subunits in different chromosome pairs. The $18 \mathrm{~S}$ sites are located proximally to the centromere, on the long arm of the large metacentric pair, coincidentally with the Ag-NOR ${ }^{+} / \mathrm{C}$-band ${ }^{+} / \mathrm{CMA}^{+} / \mathrm{DAPI}^{-}$region. The $5 \mathrm{~S}$ rDNA sites were mapped in the terminal position of chromosome pair 9, co-located with heterochromatic bands. Probes (TTAGGG) $)_{n}$ showed no ectopic sequences in any of the chromosome pairs, in addition to the telomeric sites expected.

Selene vomer showed karyotype with $2 \mathrm{n}=48$ chromosomes $(\mathrm{FN}=50)$, consisting of 46 acrocentric chromosomes and two subtelocentric chromosomes (Fig. 1; right column). Reduced heterochromatic sites are present in the pericentromeric regions of the chromosomes. As in other Selene species, a dual-color FISH with $18 \mathrm{~S}$ and $5 \mathrm{~S}$ rDNA probes showed that these sequences occupy distinct chromosome pairs. The $18 \mathrm{~S}$ rDNA sequences are located in the Ag-NOR ${ }^{+} / \mathrm{C}$-band ${ }^{+} / \mathrm{CMA}^{+} / \mathrm{DAPI}^{-}$region of the short arm on the only subtelocentric pair (pair 1). As with the other species, 5S rDNA sites were mapped in the pericentromeric position of pair 9. Telomeric sequences are located only in the terminal portions of all chromosomes.

Dual base-specific staining in all species revealed no additional positive $\mathrm{CMA}_{3}$ /negative DAPI staining beyond that already registered for the NOR region. In all species analyzed, FISH with telomeric probes (TTAGGG) exhibited signs of hybridization only in the terminal portions of chromosomes. In the Fig. 1d (center column) is shown the hybridization pattern with telomeric probe for the nucleolus organizer pair of $S$. setapinnis.

Morphometrics analyses

Data obtained through analysis of canonical variates demonstrate significant morphological separation between S. brownii, S. setapinnis, and S. vomer, primarily those of O. palometa and C. lugubris (Table 1; Fig. 2). Canonical variates one and two jointly explain $93.44 \%$ of the variation observed. Canonical variate one contributed to $85.82 \%$ of total variation, clearly separating species from 


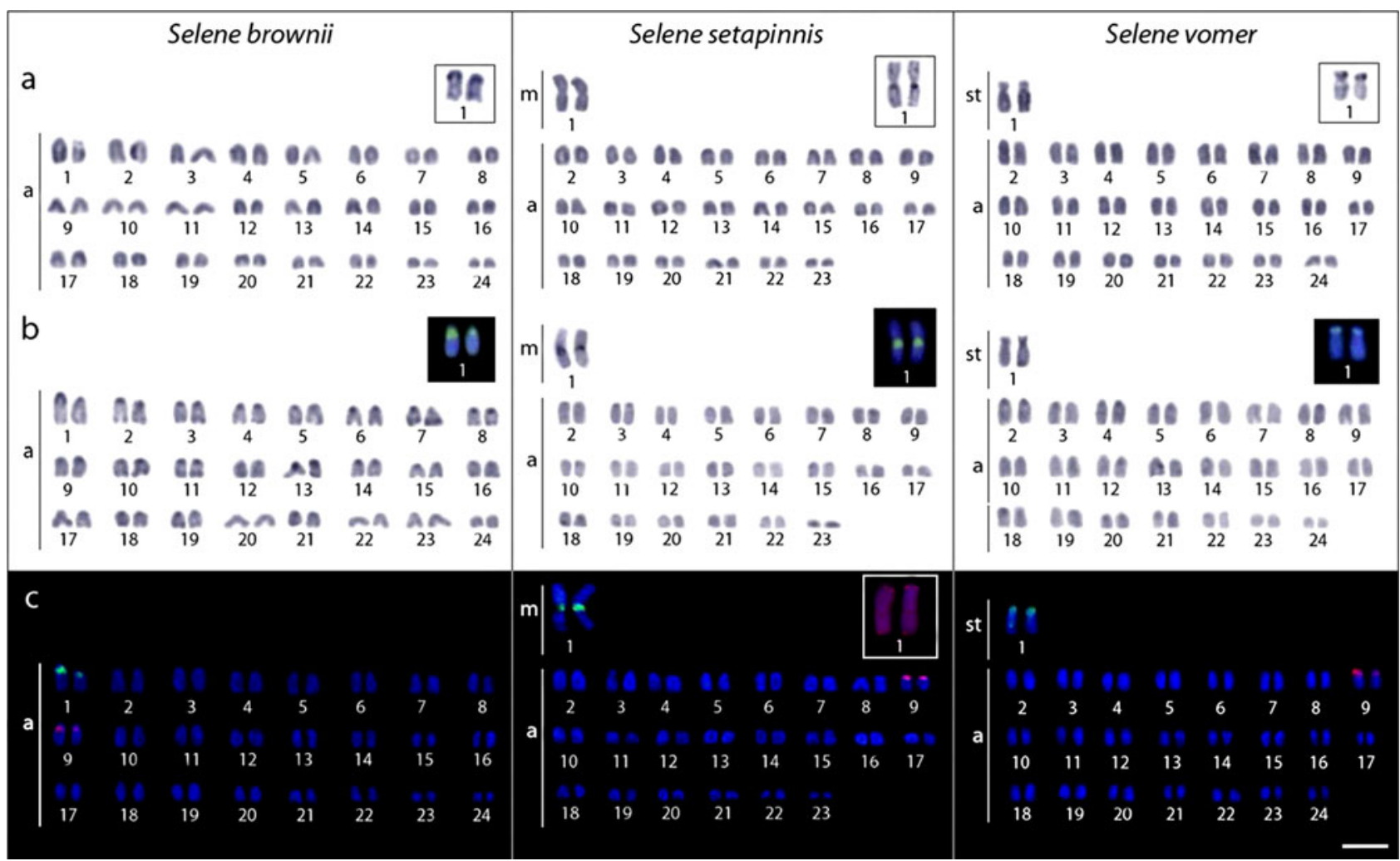

Fig. 1 Karyotypes of $S$. brownii, $S$. setapinnis, and $S$. vomer. a Conventional staining highlighting Ag-NOR sites in chromosome 1; b C-banding highlighting the NOR region with $\mathrm{CMA}_{3}{ }^{+} / \mathrm{DAPI}^{-}$ staining; c dual-color FISH with $18 \mathrm{~S}$ rDNA ( green) and $5 \mathrm{~S}$ probes (red),

the genus Selene of $O$. palometa and C. lugubris, while species $S$. brownii and $S$. setapinnis are entirely distinguishable from $S$. vomer by canonical axis 2 , which explains $7.62 \%$ of total variation.

Wireframe graphs for each species, compared with standard consensus, indicate that the distinguishing characteristic for species from the genus Selene in relation to $O$. palometa and $C$. lugubris is their deep body. In turn, $S$. vomer is clearly separated from S. brownii and S. setapinnis by the shape of its head, exhibiting a less steep profile. In addition, S. brownii and S. setapinnis differ from $S$. vomer by the deeper and more oval anteroposterior shape of their head (Fig. 2).

\section{Discussion}

Morphological diversification between Perciformes groups was, in many cases, not accompanied by pronounced karyotype diversification (Molina et al. 2002; Motta-Neto et al. 2011c). This has been reported in several families, including Haemulidae, which exhibits extensive numerical and structural chromosome conservatism among its species (Motta-Neto et al. 2011a, b, c). Nevertheless, a number of showing the location of 18S rDNA sites in the first pair and 5S rDNA in chromosome pair 9 in the karyotypes; $\mathbf{d}$ In the center column, FISH with (TTAGGG) $)_{n}$ probes showing telomeric sites in the nucleolus organizer pair of S. setapinnis. Bar $=5 \mu \mathrm{m}$ (color figure online)

Table 1 Mahalanobis distance between Carangidae species (lower diagonal) and $P$ values with permutation tests of $(\times 1,000)$ (upper diagonal)

\begin{tabular}{llllll}
\hline & C. lugubris & O. palometa & S. brownii & S. setapinnis & S. vomer \\
\hline C. lugubris & - & $<0.001$ & $<0.001$ & $<0.001$ & $<0.001$ \\
O. palometa & 18.14 & - & $<0.001$ & $<0.001$ & $<0.001$ \\
S. brownii & 30.12 & 41.51 & - & $<0.001$ & $<0.001$ \\
S. setapinis & 33.59 & 44.57 & 78.2 & - & $<0.001$ \\
S. vomer & 27.88 & 37.78 & 14.36 & 16.71 & - \\
\hline
\end{tabular}

families are characterized by chromosomal diversification, either in regard to diploid value or aspects of karyotype macrostructure (Caputo et al. 1996; Araújo et al. 2010).

In contrast with other fish families (Motta-Neto et al. 2011a), cytogenetic and morphological analyses indicated that high morphological differentiation among Selene species was also accompanied by some discernible chromosome changes, primarily diploid number variation and structural changes in one pair of chromosomes. Comparatively, S. brownii and S.setapinnis exhibited greater morphological similarity between them. However, the karyotype of S. brownii maintains more basal characteristics of the order 
Fig. 2 Canonical variates projection of body shape measurements for $O$. palometa (black stars), C. lugubris (white circles), S. brownii (black squares), S. setapinnis (white stars), and $S$. vomer (black circles). Schematic drawings show comparisons between species and consensus shape

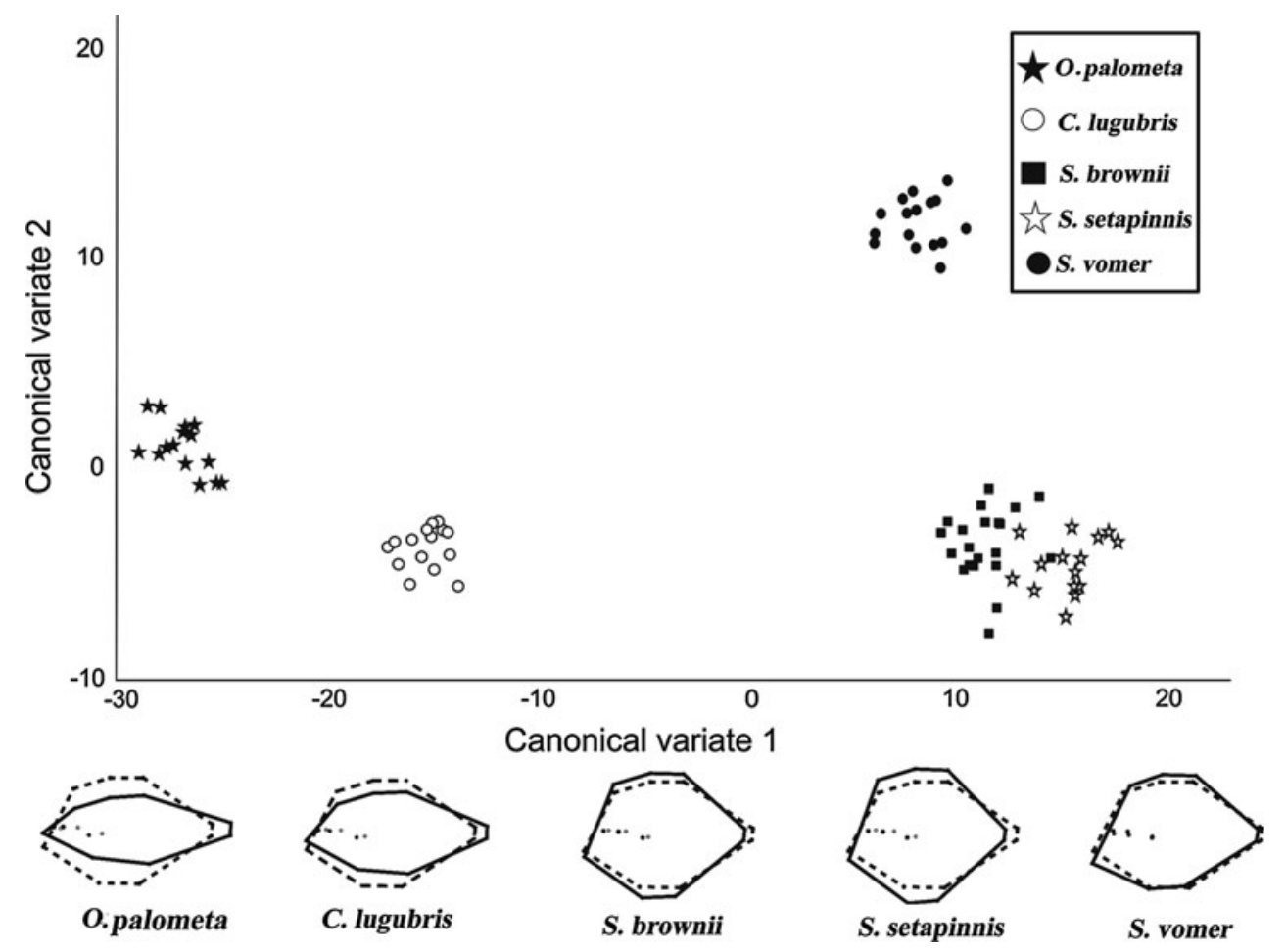

Perciformes, such as $2 n=48$ acrocentric chromosomes, simple ribosomal sites, and reduced heterochromatin (Brum 1996). The karyotype of S.setapinnis diverges from S. brownii in that it displays a lower diploid value $(2 n=46)$ and large metacentric pair, suggesting a clear Robertsonian translocation events as the origin of the pair.

Ribosomal sites, located proximally to the centromere on the long arm of this pair and identified by Ag-NOR and mapping of $18 \mathrm{~S}$ rDNA sequences, are compatible in size and position with those found in the conserved karyotype of $S$. brownii, which reinforced this hypothesis. Thus, S.brownii and S.setapinnis are completely distinct with regard to their cytogenetic patterns. Involvement by an ancestral chromosome pair, bearing NOR sites, in the formation of a single metacentric pair in S. setapinnis suggests a more derived condition for this species in relation to S. brownii. Unlike S.brownii and S.setapinnis, the chromosome bearing NOR sites in $S$. vomer is subtelocentric, indicating the occurrence of pericentric inversion in the formation of this pair, exclusive to this species. In conjunction, these results suggest chromosome rearrangement is favored by the presence of ribosomal sites. In fact, there are indications that heterochromatin congruent to NORs may play a role in evolutionary rearrangements involving NOR-bearing chromosomes (Fujiwara et al. 1998).

In the family Carangidae, approximately $85 \%$ of species display $2 n=48$ chromosomes. Of these, $30 \%$ have karyotypes formed exclusively by acrocentric chromosomes (Chai et al. 2009), representing a basal characteristic for Perciformes. As such, numerical and structural alterations in this pattern are indicative of more derived karyotypes (Molina 2007), as in S.setapinnis and S. vomer. On the other hand, presence of bibrachial chromosomes demonstrates evolutionarily more dynamic karyotypes in Carangidae when compared with some other marine Perciformes families, such as Chaetodontidae and Sciaenidae (Galetti et al. 2006; Accioly and Molina 2008).

Among primary karyotype diversification events, pericentric inversions play an important role in the family Carangidae. However, chromosome polymorphisms related to Robertsonian translocations in Trachurus and Seriola (Vitturi et al. 1986) indicate these occurrences also contribute to karyotype diversification in Carangidae and may become established in some species, as observed in S. setapinnis.

In light of the extensive karyotypical conservatism presented by some groups of Perciformes, NORs may be inefficient cytotaxonomic markers for some species (Molina and Galetti 2004). However, NORs located in chromosomes involved in rearrangements, as in Carangidae (Caputo et al. 1996; Sola et al. 1997; Rodrigues et al. 2007; present study), make them potentially effective taxonomic and population approaches for this group. Although species analyzed contained a nucleolar organizer pair as a specific marker, the genus Selene displayed several conservative traits in its karyotypes. These include a large number of acrocentric chromosomes, simple 18S rDNA sites not syntenic with 5S-rRNA genes, GC-rich regions coincident with NORs, $5 \mathrm{~S}$ rDNA sites situated in chromosomal pairs corresponding to the presence of low heterochromatic content primarily in 
pericentromeric regions. These characteristics have been identified as basal to Perciformes (Galetti et al. 2006; Molina 2007) and indicative of significant chromosome conservatism with low evolutionary dynamics. (Motta-Neto et al. 2011a, b, c). Similarly to NORs, 5S rDNA sites have proven to be phylogenetically discriminatory markers between several species and populations of marine fish (Motta-Neto et al. 2011a, b). Some cases have identified possible participation by $5 \mathrm{~S}$ sites in chromosome rearrangements (Molina and Galetti 2002). Nevertheless, among Selene species, 5S sequences have demonstrated a conserved condition with low evolutionary dynamics.

Mapping of telomeric sequences has shown chromosomal fusion points in some fish species (Phillips and Reed 1996; Fontana et al. 1998). Selene brownii, S. setapinnis and $S$. vomer sequences (TTAGGG) $)_{\mathrm{n}}$ are exclusively located in the terminal portions of chromosomes. In $S$. setapinnis $(2 n=46)$, the reduced diploid number observed in the ancestral condition $(2 n=48)$ is attributed to centric fusion. In such cases, acrocentric/telocentric chromosomes, which are now united by their centromeres, may maintain fragments of their telomeric DNAs at the points of the fusion, with the occurrence of interstitial telomeric sites (ITS). However, several centric fusion events did not indicate the presence of ITS, as observed in the large metacentric pair of $S$. setapinnis, likely due to loss of these sequences during fusion (Slijepcevic 1998). Nevertheless, the $18 \mathrm{~S}$ rDNA site in this chromosomal pair is adjacent to the point of fusion, that is, proximal to the centromere. A similar situation was recorded in fish from the genus Chromis, where 5S sites were contiguous to chromosome fusion regions and no ITS sites were detected (Molina and Galetti 2002). Similarly, decondensed 5S rDNA sites, interspaced by ITS sites, are indicative of chromosome fusions (Rosa et al. 2012).

Morphologically, Carangidae are characterized by a compressed, though highly variable, body shape, whereas species from the genera Decapterus and Trachurus have slender bodies, and those from Selene exhibit taller bodies (Gushiken 1988; Reed et al. 2002). As such, three body patterns are found in the genus Selene: (1) steep head profile with elongated dorsal and anal fins, seen in $S$. vomer, (2) head profile rounded on the top and very steep, with short dorsal and anal fins, present in S. brownii and S. setapinnis and, (3) and intermediary profile to the previous two, found in S. osterdii (Smith-Vaniz 1984). Although these body characteristics appear to indicate substantial derivation among carangids, no study has established how morphological evolution with in the group occurred. Phylogenetic inferences, as yet unconfirmed, based on Cit B sequences (Reed et al. 2001), suggest that the short dorsal and anal fins, such as those found in $S$. brownii and S. setapinnis, are derived. However, this hypothesis is not substantiated by cytogenetic data, since $S$. brownii displays a karyotype with characteristics considered the most basal among the three species analyzed here.

As such, in light of the apparent inconsistency between cytogenetic and molecular data, aspects of body shape were quantified in order to determine possible relationships between the species. Comparison of the body pattern of Selene species, polarized by members of the genus Oligoplites (O.palometa), which are phylogenetically more basal and Caranx (C. lugubris), a more modern group (Reed et al. 2002), enabled quantification of the morphological amplitude between these species (Table 1). Morphological patterns are notably different among Selene and representatives of the genera Oligoplites and Caranx. Selene brownii and S.setapinnis show greater morphological proximity in species analyzed. In other words, S. setapinnis exhibits a more divergent pattern in relation to the basal external group, followed by $S$. brownii, while $S$. vomer differs more from these two species and is less divergent from O.palometa and C. lugubris. Thus, if these patterns are an accurate representation of phylogenetic relationships with in the family, this would suggest that chromosome rearrangements occur independently between species and, as such, would not be valid phylogenetic markers.

Morphological patterns are often indicators of the lifestyle of a species (Karr and James 1975; Wainwright and Reilly 1994). In fact, strong associations have been observed between basic shape and ecological function (Winemiller 1992). Morphological analyses in Selene suggest its steeper head profile is a derived characteristic, effectively separating $S$. brownii and S. setapinnis from S. vomer, which exhibits a less steep profile. However, significant differences in the anteroposterior axis are also discriminatory for the species. Therefore, the oval and deeper body characteristic of $S$. setapinnis, followed by a more oblong pattern in $S$. brownii, is sequentially enhanced in $S$. vomer, C. lugubris, and $O$. palometa. In association with these features, differences in the caudal peduncle were also detected in the five species investigated. This is a discriminating characteristic in juvenile phases of Selene, as well as other species (Winans and Nishioka 1987; Lima-Filho et al. 2006).

Data obtained in this study appear to indicate a lack of evolutionary synchrony between morphological changes and karyotype alterations in Selene species, which has also been suggested for other families of Perciformes (Molina et al. 2002; Motta-Neto et al. 2011c). However, this is not a universal occurrence, since distinct situations have also been observed among Perciformes. Thus, integrating cytogenetic approaches with body patterns has shown combined variation in both parameters for other species, such as Bathygobius soporator (Lima-Filho et al. 2012). In addition to corroborating molecular evidence identifying $S$. brownii and S. setapinnis as distinct taxa (Reed et al. 2001, 
2002), cytogenetic aspects and body shape patterns shown here also highlight divergences of these two species with the Atlantic lookdown, S. vomer. The reduced species diversity observed in the genus Selene, combined with morphological peculiarities and low general variation of karyotypes among its species, makes this taxon an effective and interesting evolutionary model within the family Carangidae, deserving of more detailed investigation.

Acknowledgments We are grateful to the National Council for Scientific and Technological Development (CNPq) for financial support (Process No. 556793/2009-9), IBAMA (Process No. 19135/1), Federal University of Rio Grande do Norte for providing the means to conduct this study.

\section{References}

Accioly IV, Molina WF (2008) Cytogenetic studies in Brazilian marine Sciaenidae and Sparidae fishes (Perciformes). Genet Mol Res 7:358-370

Araújo WC, Martiınez PA, Molina WF (2010) Mapping of ribosomal DNA by FISH, EcoRI digestion and replication bands in the cardinalfish Apogon americanus (Perciformes). Cytologia 75:109-117

Barros-e-Silva AE, Guerra M (2010) The meaning of DAPI bands observed after C-banding and FISH procedures. Biotech Histochem 85:115-125

Brum MJI (1996) Cytogenetic studies of Brazilian marine fish. Braz J Genet 19:421-427

Brum MJI, Galetti PM Jr (1997) Teleostei plan ground karyotype. J Comput Biol 2:91-102

Caputo V, Marchegftani F, Olmo E (1996) Karyotype differentiation between two species of carangid fishes, genus Trachurus (Perciformes: Carangidae). Mar Biol 127:193-199

Chai X, Lu LR, Clarke S (2009) Karyotype analysis of the yellowtail kingfish Seriola lalandi lalandi (Perciformes: Carangidae) from South Australia. Aquac Res 40:1735-1741

Dryden IL, Mardia KV (1998) Statistical shape analysis. Wiley Press, New York

Fontana F, Lanfredi M, Chicca MI, Aiello V, Rossi R (1998) Localization of the repetitive telomeric sequence (TTAGGG) $)_{n}$ in four sturgeon species. Chromosome Res 6:303-306

Fujiwara A, Abe S, Yamaha E, Yamazaki F, Yoshida MS (1998) Chromosomal localization and heterochromatin association of ribosomal RNA genes loci and silver stained nucleolar organizer regions in salmonid fishes. Chromosome Res 6:463-471

Galetti PM Jr, Molina WF, Affonso PRAM, Aguilar CT (2006) Assessing genetic diversity of Brazilian reef fishes by chromosomal and DNA markers. Genetica 126:161-177

Gold LC, Shipley NS, Powers PK (1990) Improved methods for working with fish chromosomes with a review of metaphase chromosome banding. J Fish Biol 37:563-575

Griffiths SP (2000) The use of clove oil as an anaesthetic and method for sampling intertidal rockpool fishes. J Fish Biol 57:1453-1464

Gushiken S (1988) Phylogenetic relationships of the perciform genera of the family Carangidae. Jpn J Ichthyol 34:443-461

Hatanaka T, Galetti PM Jr (2004) Mapping of the 18S and 5S ribosomal RNA genes in the fish Prochilodus argenteus Agassiz, 1829 (Characiformes, Prochilodontidae). Genetica 122:239-244

Howell WM, Black DA (1980) Controlled silver-staining of nucleolus organizer regions with a protective colloidal developer: a 1-step method. Experientia 36:1014-1015
Ijdo JW, Wells RA, Baldini A, Reeders ST (1991) Improved telomere detection using a telomere repeat probe (TTAGGG) $)_{n}$ generated by PCR. Nucl Acids Res 19:4780

Karr JR, James FC (1975) Eco-morphological configurations and convergent evolution of species and communities. In: Cody ML, Diamond JM (eds) Ecology and evolution of communities. Harvard University Press, Cambridge

King M (1993) Species evolution: The role of chromosome change. Cambridge University Press, Cambridge

Klingenberg CP (2008) MorphoJ, Faculty of Life Sciences, University of Manchester, Manchester. Available from: http://www. flywings.org.uk/MorphoJ.page.htm

Levan A, Fredga K, Sandberg AA (1964) Nomenclature for centromeric position on chromosomes. Hereditas 52:201-220

Lima-Filho JM, Lessa R, Stosic B, Duarte Neto PJ, Vieira JW (2006) Morphological discrimination in juveniles of two Selene species (Teleostei: Carangidae) using truss net distances. Braz Arch Biol Technol 49:231-238

Lima-Filho PA, Cioffi MB, Bertollo LAC, Molina WF (2012) Chromosomal and morphological divergences in Atlantic populations of the frillfin goby Bathygobius soporator (Gobiidae, Perciformes). J Exp Mar Biol Ecol 434-435:63-70

Martins C, Galetti PM Jr (1999) Chromosomal localization of 5S rDNA genes in Leporinus fish (Anostomidae, Characiformes). Chromosome Res 7:363-367

Molina WF (2007) Chromosomal changes and stasis in marine fish groups. In: Pisano E, Ozouf-Costaz C, Foresti F, Kapoor BG (eds) Fish cytogenetics. Enfield Science Publishers, pp 69-110

Molina WF, Galetti PM Jr (2002) Robertsonian rearrangements in the reef fish Chromis (Perciformes, Pomacentridae) involving chromosomes bearing 5S rRNA genes. Genet Mol Biol 25:373-377

Molina WF, Galetti PM Jr (2004) Karyotypic changes associated to the dispersive potential on Pomacentridae (Pisces, Perciformes). J Exp Mar Biol Ecol 309:109-119

Molina WF, Maia-Lima FA, Affonso PRAM (2002) Divergence between karyotypical pattern and speciation events in Serranidae fish (Perciformes). Caryologia 55:299-305

Molina WF, Alves DOE, Araújo WC, Martinez PA, Silva MFM, Costa GWWF (2010) Performance of human immunostimulant agents in the improvement of fish cytogenetics. Genet Mol Res 9:1807-1814

Motta-Neto CC, Cioffi MB, Bertollo LAC, Molina WF (2011a) Extensive chromosomal homologies and evidence of karyotypic stasis in Atlantic grunts of the genus Haemulon (Perciformes). J Exp Mar Biol Ecol 401:75-79

Motta-Neto CC, Cioffi MB, Bertollo LAC, Molina WF (2011b) Molecular cytogenetic analysis of Haemulidae fish (Perciformes): evidence of evolutionary conservation. J Exp Mar Biol Ecol 407:97-100

Motta-Neto CC, Lima-Filho PA, Araújo WC, Bertollo LAC, Molina WF (2011c) Differentiated evolutionary pathways in Haemulidae (Perciformes): karyotype stasis versus morphological differentiation. Rev Fish Biol Fish. doi:10.1007/s11160-011-9236-4

Phillips RB, Reed KM (1996) Application of fluorescence in situ hybridization (FISH) techniques to fish genetics: a review. Aquaculture 140:197-216

Pinkel D, Straume T, Gray JW (1986) Cytogenetic analysis using quantitative, high-sensivity, fluorescence hybridization. Proc Natl Acad Sci USA 83:2934-2938

Reed DLM, Gravelle J, Carpenter KE (2001) Molecular systematics of Selene (Perciformes: Carangidae) based on cytochrome $\mathrm{b}$ sequences. Mol Phylogenet Evol 21:468-475

Reed DL, Carpenter KE, Gravelle MJ (2002) Molecular systematics of the Jacks (Perciformes: Carangidae) based on mitochondrial cytochrome $\mathrm{b}$ sequences using parsimony, likelihood, and Bayesian approaches. Mol Phylogenet and Evol 23:513-524 
Rodrigues MM, Baroni S, Almeida-Toledo LF (2007) Karyological characterization of four marine fish species, genera Trachinotus and Selene (Perciformes: Carangidae), from the Southeast Brazilian coast. Cytologia 72:95-99

Rohlf FJ (2004) TpsDig. Department of Ecology and Evolution. New York, Stony Brook

Rohlf FJ, Slice DE (1990) Methods for comparison of sets of landmarks. Syst Zool 39:40-59

Rosa KO, Ziemniczak K, Barros AV, Nogaroto V, Almeida MC, Cestari MM, Artoni RF, Vicari MR (2012) Numeric and structural chromosome polymorphism in Rineloricaria lima (Siluriformes: Loricariidae): fusion points carrying 5S rDNA or telomere sequence vestiges. Rev Fish Biol Fisheries 22:739-749

Slijepcevic P (1998) Telomeres and mechanisms of Robertsonian fusion. Chromosoma 107:136-140

Smith-Vaniz, WF (1979) Family Carangidae. In: Fischer W (ed) FAO species identification sheets for fisheries purposes: Western Central Atlantic Fishing Area 31. FAO, Rome

Smith-Vaniz WF (1984) Carangidae: elationships. In: Moser HG, WJ Richards, DM Cohen,Fahay MP, AW Kendall Jr and Richardson
SL,(eds). Ontogeny and systematics of fishes. American Society of Ichthyology and Herpetology Special Publications. 1:522-530

Sola L, Cipelli O, Gornung E, Rossi AR, Andaloro F, Crosetti D (1997) Cytogenetic characterization of the greater amberjack, Seriola dumerili (Pisces: Carangidae), by different staining techniques and fluorescence in situ hybridization. Mar Biol 128:573-577

Sumner AT (1972) A simple technique for demonstrating centromeric heterochromatin. Exp Cell Res 75:304-306

Vitturi R, Mazzola A, Macaluso M, Catalano E (1986) Chromosomal polymorphism associated with Robertsonian fusion in Seriola dumerili (Risso, 1810) (Pisces: Carangidae). J Fish Biol 26:529-534

Wainwright PC, Reilly SM (1994) Ecological morphology: integrative organism biology. The University of Chicago Press, Chicago

Winans GA, Nishioka RS (1987) A multivariate description of change in body shape of coho salmon (Oncorhynchus kisutch) during smoltification. Aquaculture 66:235-245

Winemiller KO (1992) Ecomorphology of freshwater fishes. Ecological divergence and convergence in freshwater fishes. Natl Geogr Res Explor 8:308-327 